\title{
RANCANG BANGUN GAME PEWAYANGAN ANOMAN OBONG BERBASIS ANDROID MENGGUNAKAN METODE PROTOTYPE
}

\author{
Nanda Fitra Wahyuono \\ legendajadilah@gmail.com \\ Sekolah Tinggi Teknik Malang
}

\begin{abstract}
Abstrak - Wayang merupakan salah satu seni budaya Indonesia yang memiliki nilai-nilai dalam kehidupan masyarakat. Seiring dengan perkembangan zaman ketertarikan generasi muda terhadap wayang tergeser oleh budaya barat yang lebih modern. Dengan perkembangan teknologi smartphone saat ini dapat dijadikan sebagai media informasi untuk pengenalan budaya wayang. Tujuan pembuatan aplikasi game pewayangan anoman obong berbasis adalah untuk dapat membantu pengguna dalam mempelajari wayang dengan mudah dan efisien
\end{abstract}

Metode yang digunakan dalam rancang bangun game adalah metode prototype. Aplikasi game dibuat dengan menggunakan game engine unity, konsep desain menggunakan coreldraw, Adobe Audition untuk editing audio, script writer menggunakan mono develop. Hasil penelitian berupa aplikasi game pewayangan anoman obong berbasis android dengan ukuran $16 \mathrm{Mb}$ yang memadukan permainan dengan cerita anoman obong.

\section{PENDAHULUAN}

Bangsa indonesia adalah bangsa yang mempunyai berbagai macam seni budaya daerah yang berkembang di dalam masyarakatnya. Salah satu seni budaya bangsa Indonesia yang paling menonjol di antara banyak karya budaya lainnya adalah wayang. Cerita Pewayangan yang populer dimasyarakat masa kini yaitu Ramayana dan Mahabarata. Salah satu tokoh dalam cerita Ramayana adalah Hanoman. Di masa sekarang ketertarikan masyarakat terutama generasi muda terhadap cerita pewayangan semakin terkikis oleh ceritacerita fantasi baru dari luar negeri, tidak menutup kemungkinan kesenian wayang kulit dapat punah karena semakin sedikit peminatnya (Andianto,2015). Rendahnya pemahaman terhadap cerita pewayangan dikalangan masyarakat dikarenakan cara penyampaian wayang yang dianggap terlalu sederhana. Maka diperlukan sebuah media untuk mempermudah penyampaian informasi.

Salah satu cara pengenalan kembali cerita pewayangan adalah memanfaatkan teknologi modern pada smartphone yang menjadi unggulan di dunia teknologi mobile yaitu platform Android. Aplikasi yang cukup berkembang sangat pesat 
adalah game. Game yang terdapat unsur budaya tradisional akan menjadi sebuah game yang unik baik itu dari segi karakter maupun dari segi bermainnya. Dengan memainkan game tersebut secara tidak langsung pemainnya telah mengenal budaya tradisional.

\section{METODE PENELITIAN}

\section{A. Jenis Penelitian}

Jenis penelitian dalam perancangan sistem informasi menerapkan tahap-tahap yang ada dalam metode prototype yaitu: (1) komunikasi dan data awal; (2) quick design; (3) pembentukan prototype; (4) evaluasi prototype; (5) perbaikan prototype; (5) produksi akhir.

\section{B. Jenis Data}

Dalam hal ini jenis data yang digunakan penulis adalah jenis penelitian kualitatif. Dimana data dan informasi yang diperoleh ditarik makna dan kesimpulan secara deskriptif dan tanpa menggunakan angka karena dalam perancangan ini lebih mengutamakan prosesnya.

\section{Sumber Data}

Dalam penelitian ini penulis menggunaka dua sumber data yaitu :

\section{Data Primer}

Data primer materi cerita pewayangan diperoleh dari Ki Dalang Dasir, dan untuk sumber data observasi diperoleh dari peserta didik SMKN 1 Sambeng Kabupaten Lamongan.

2. Data Sekunder

Data ini diperoleh dengan menggunakan studi literature yang dilakukan terhadap beberapa informasi dari buku dan diperoleh dari catatan catatan dan data yang berhubungan dengan penelitian dari internet.

D. Populasi

Populasi merupakan sumber asal sampel diambil. Dalam penelitian ini adalah peserta didik di SMKN 1 Sambeng Kabupaten Lamongan.

E. Sample

Sample adalah bagian dari jumlah dan karakteristik yang dimiliki oleh populasi tersebut (Sugiono, 2012). Untuk pengambilan sample, peneliti menggunakan teknik simple random sampling, karena pengambilan sample dari populasi dilakukan dengan secara acak tanpa memperhatikan strata yang ada dalam populasi.

\section{HASIL DAN PEMBAHASAN}

\section{A. Desain Perancangan}

Secara garis besar konsep dari permainan ini dibuat semenarik mungkin, Karena permainan ini ditujukan untuk 
anak-anak atau peserta didik. konsepnya sederhana, pemain yang berperan sebagai tokoh Anoman akan menjelajah melewati angkasa, samudera hingga negeri alengka. Pemain juga harus jeli dan lincah agar bisa menghindari dari rintangan disetiap perjalanan, karena jika Anoman terkena rintangan maka nyawa akan berkurang dan jika nyawa habis maka permainan akan memulai lagi dari awal.

\section{B. Storyboard}

Pada storyboard digambarkan perencanaan tampilan yang nantinya akan digunakan juga dijelaskan dari setiap layarnya, dengan demikian proses building prototipe akan menjadi terarah. Pada perancangan Storyboard ini dibuat 6 tampilan, yaitu :

\section{1). Storyboard Menu Utama}

Pada scene ini adalah storyboard tampilan utama dari aplikasi.

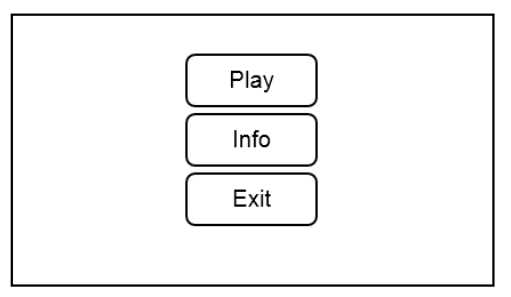

\section{2). Storyboard Menu Info}

Pada halaman ini pengguna dapat mengetahui informasi seputar tokoh pewayangan dan juga informasi tentang pengembang.

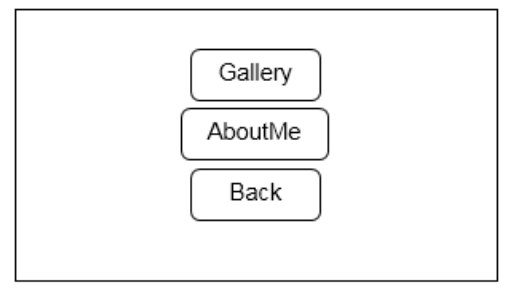

\section{3). Storyboard Gallery}

Pada halaman ini akan menampilkan informasi tentang tokoh pewayangan anoman obong.

\begin{tabular}{l}
112 \\
4456 \\
\hline
\end{tabular}

\section{4). Storyboard Menu Level}

Pada halaman ini pengguna dapat memilih level permainan.

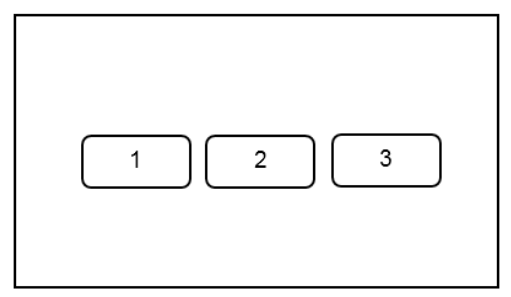

\section{5). Storyboard Story}

Pada halaman ini berupa gambar dan teks yang menceritakan sekilas tentang cerita pewayangan anoman obong.

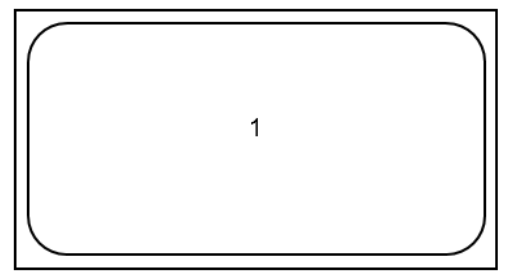


6). Storyboard Game Scene

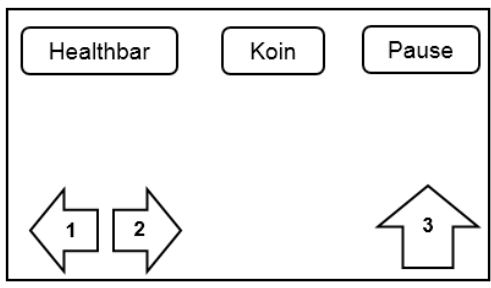

Keterangan :

1)Healthbar : Informasi nyawa pemain

2)Koin : Menampilkan infomasi

koin

3)Tombol Pause : Menghentikan permainan sejenak atau menampilkan Menu Pop Up Pause.

4) Navigasi 1,2,3 : Tombol navigasi arah kiri, kanan dan melompat.

\section{LAYOUT APLIKASI GAME}

Implementasi merupakan proses pembangunan komponen-komponen pokok suatu sistem. komponen tersebut dibangun berdasarkan desain dan rancangan yang telah dibuat sebelumnya. Berikut adalah interface Game Pewayangan Anoman Obong yang telah dibuat.

A. Tampilan Splash Screen Aplikasi

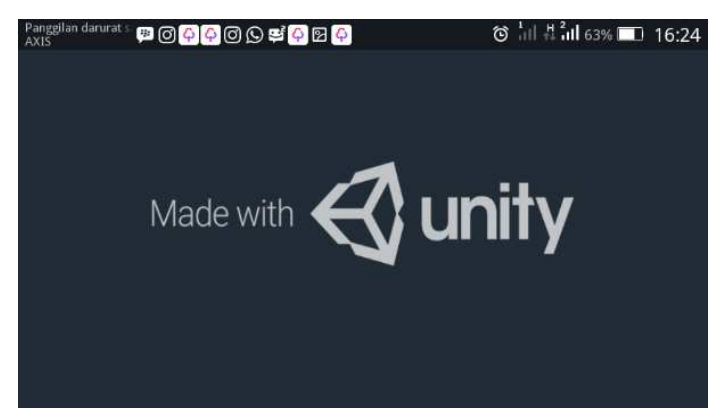

Gambar 6.14 Tampilan Splash Screen Aplikasi

(Sumber : Peneliti)

\section{B. Tampilan Main Menu}

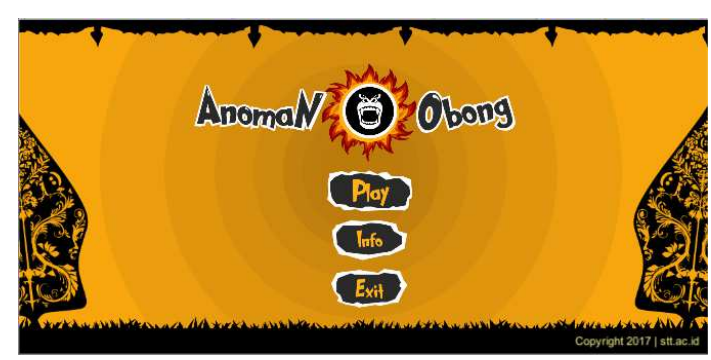

Gambar 6.15 Tampilan Main Menu

(Sumber : Peneliti)

C. Tampilan Menu Level

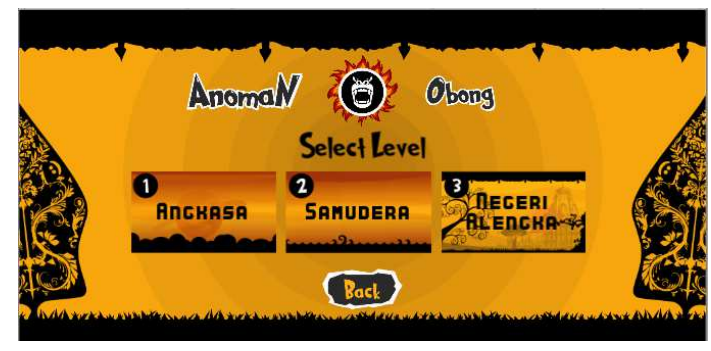

Gambar 6.16 Tampilan Menu Level

(Sumber : Peneliti)

D. Tampilan Story 


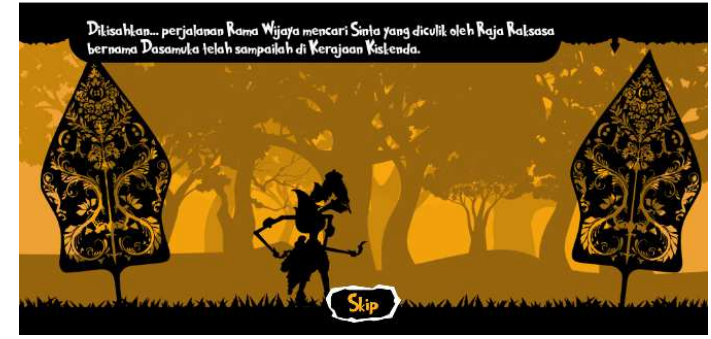

Gambar 6.17 Tampilan Story

(Sumber : Peneliti)

E. Tampilan Area Permainan

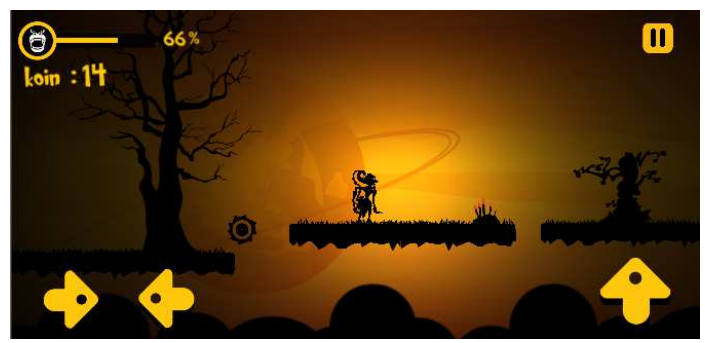

Gambar 6.18 Tampilan Area Permainan (Sumber : Peneliti)

F. Tampilan Panel Pause

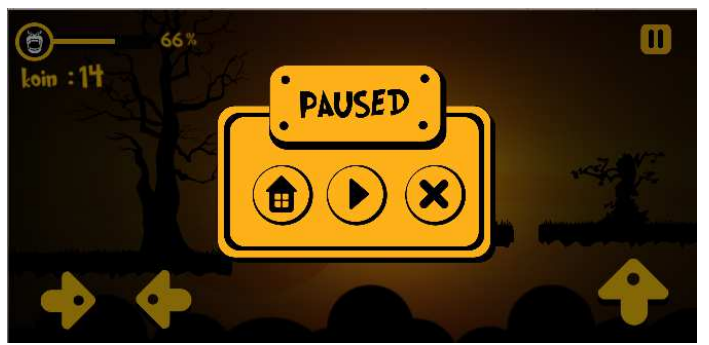

Gambar 6.19 Tampilan Panel Pause

(Sumber : Peneliti)

\section{G. Tampilan Menu Info}

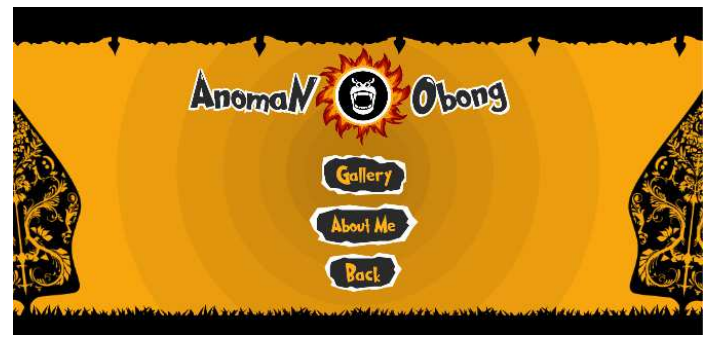

Gambar 6.20 Tampilan Menu Info

(Sumber : Peneliti)
H. Tampilan Menu Gallery

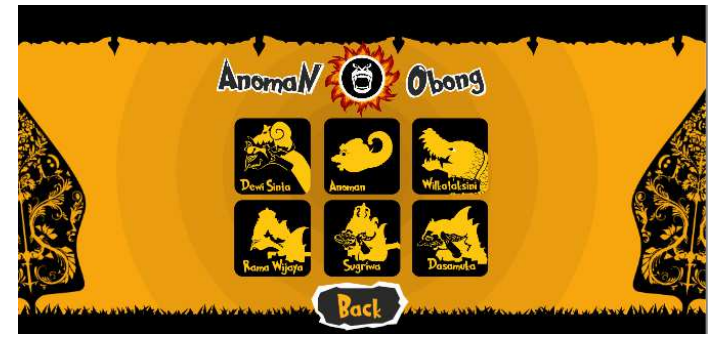

Gambar 6.21 Tampilan Menu Gallery

(Sumber : Peneliti)

I. Tampilan Pop Up Gallery

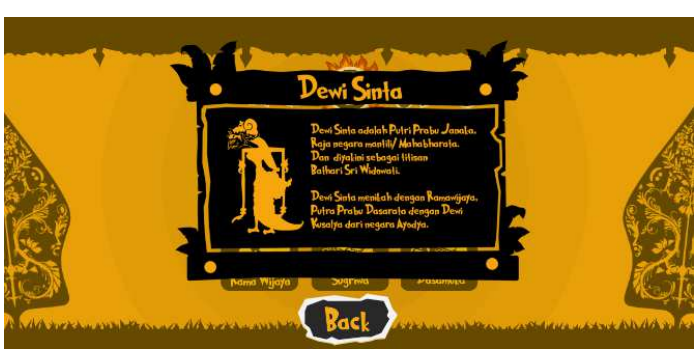

Gambar 6.22 Tampilan Pop Up Gallery

(Sumber : Peneliti)

\section{KESIMPULAN}

Berdasarkan hasil permasalahan serta implementasi dan pengujian yang dilakkukan oleh peneliti, maka dapat ditarik kesimpulan sebagai berikut :

1. Telah dirancang dan dibuat game pewayangan Anoman Obong yang telah disisipkan cerita pewayangan anoman obong dengan desain karakter dan alur cerita yang dapat menarik pemain dalam memainkan game.

2. Kontrol dan User Interface pada aplikasi game pewayangan Anoman Obong mudah dipahami pemain. 
3. Aplikasi game pewayangan anoman obong dapat menjadi media informasi yang efektif dalam menambah wawasan tentang cerita pewayangan anoman obong. Dibuktikan dengan hasil angket dari responden yaitu dengan prosentase $71 \%$, hasil angket dari ahli media dengan prosentase $86 \%$, serta hasil dari dua ahli materi yaitu dari guru bahasa jawa dengan prossentase $100 \%$ dan hasil angket dari dalang dengan prosentase $96 \%$. Dari hasil angket yang telah dicantumkan maka aplikasi layak untuk digunakan.

\section{DAFTAR RUJUKAN}

Agustinus Kisroh. Dr. Eng. Steven R.

Sentinuwo, \& Brave A. Sugiarso, 2015, Prototipe Game Petualangan Pariwisata Sulawesi Utara. Jurnal. Teknik Informatika, Universitas Sam Ratulangi. Manado

Chandra. Ramadhan Adhi, 2015. Perancangan Dan Pembuatan Game Anoman Gesit Menggunakan Html5 Dan Javascript. Jurnal. Sekolah Tinggi Manajemen Informatika Dan
Komputer Amikom Yogyakarta. Yogyakarta

Aprianto Dhoni. 2016. Aplikasi Pengenalan Tokoh Wayang Kulit dan Lagu Jawa Interaktif Berbasis Android. Skripsi. Program Studi Informatika Fakultas Komunikasi Dan Informatika Universitas Muhammadiyah Surakarta. Surakarta.

Hidayat. Kardila Rohmat. 2013. Rancang Bangun Game Mobile The Wars Of Wayang Untuk Platform Android, Naskah Publikasi, Sekolah Tinggi Manajemen Informatika Dan Komputer Amikom Yogyakarta. Yogyakarta.

Kurniawan, $\quad$ Citra. 2017. Pengembangan Model Pembelajaran 3D Display System Berbasis Holografi. Sinteks: Jurnal Teknik : 5 (2). Sekolah Tinggi Teknik Malang

Kurniawan. Wahyu Arif. 2014. Perancangan Aplikasi Game "Hanoman The Incredible Warrior" Menggunakan Adobe 
Flash. Jurnal. Jurusan teknik informatika. Sekolah Tinggi

Manajemen Informatika Dan Komputer Amikom Yogyakarta. Yogyakarta

Prahara. Aditya Yoga \& Taqwa Hariguna. 2010. Rancang Bangun Game Pertempuran Lakon Wayang Sebagai Sarana Pengenalan Tokoh Pewayangan Indonesia. Jurnal Telematika. Teknik Informatika, STMIK Amikom Purwokereto. Purwokerto

Rizal Andianto. 2015. Aplikasi Ensiklopedia Tokoh-Tokoh Wayang Purwa Dan Silsilahnya Berbasis Android. Skripsi. Sekolah Tinggi Manajemen Informatika Dan Komputer Amikom Yogyakarta. Yogyakarta.

Sugiyono. 2012. Metode penelitian kualitatif, kuantitatif, dan $R \& D$. CV Alfabeta : Bandung. 